\title{
Canadian Association of Gastroenterology Practice Guideline for informed consent - gastrointestinal endoscopy
}

\author{
H Miller MacSween MD FRCPC
}

$\mathrm{I}$ nformed consent has undergone a transformation from an ethical concept to a legal doctrine. It is based on the ethical principles of self-determination and autonomy. Over the past several years, courts have established physician liability based on the failure to obtain adequate informed consent. It is the duty of all gastrointestinal endoscopists to obtain legally adequate informed consent before performing any endoscopic procedure.

The Canadian Medical Protective Association publication Consent: A Guide for Canadian Physicians outlines how consent is viewed in the Canadian jurisdiction. The standard consent form on the last page of the brochure is advised, and a specific consent form for endoscopy is not recommended. The principles of informed consent apply to any intervention and are not unique to gastrointestinal endoscopy. A signed consent form has undoubted evidential value, but is often simply an administrative step that does not allow physicians to review adequately the information that patients need to base their decisions for or against treatment.

Background information in the form of information sheets, brochures and similar materials are useful adjuncts to the consent process, but should be provided well in advance of signing the consent form. Courts have made it clear that except in urgent and pressing circumstances, patients must be given adequate opportunity to consider the implications of what they are consenting to. Regardless of what supplementary methods are employed to provide patients with information before consent, it must be emphasized that they can only supplement and not replace dialogue with the patient. For evidential purposes, a contemporaneous note should be

\section{SPONSORS AND VALIDATION}

This practice guideline, based on review of published data and consultation with the Canadian Medical Protective Association, was developed by $\mathrm{H}$ Miller MacSween MD FRCPC and was reviewed by:

- The Practice Affairs Committee

- Canadian Association of Gastroenterology (CAG) Governing Board

- CAG Endoscopy Committee

- CAG Program Directors Committee.

made confirming that the supplementary material was provided and that after reviewing it the patient was given an opportunity to ask questions about it before consenting. In Canada, the courts rely heavily on progress notes if it is clear that they were made contemporaneously with the events they recorded. When consent explanations are given it is recommended that the doctor note briefly some of the significant points raised in conversation with the patient. Such notations, particularly if they identify questions or special concerns expressed by the patient, can validate the consent process better than any other documentation. If the note on the office or hospital chart records something relevant to the discussion with the patient, it will serve as much more credible evidence than the recollection of any of the parties involved in a lawsuit. 
In Canada, the court uses a two-step system to judge the adequacy of consent. The first step involves an assessment by the court of whether the physician met what would be considered to be the standard of a normal, prudent practitioner of the same experience and standing in outlining the diagnosis, proposed treatment, risks and alternatives, including the risk of no treatment. The second step for the court is to assess whether a reasonable patient, having been informed of risks that were allegedly not mentioned, would have agreed to proceed with the particular procedure or treatment. The risks and possible complications of the procedure must be described. Not every possible risk or complication needs to be disclosed, but those that occur with significant frequency and those of a serious nature should be presented. In law, risk with severe consequences, even if it is minuscule, is considered a "material" risk and must be disclosed. If drugs are to be used the endoscopist should inform the patient of their hazards and risks.

In Canada, patients who are competent, even in the face of an emergency situation, may make decisions to refuse treatment even though that refusal may result in harm or death to the patient. In emergency situations regarding incompetent patients, in the absence of a legally recognized substitute decision maker, physicians have a duty to provide care that is life and limb saving.

Canadian endoscopists are advised to be familiar with the updated publication of the Canadian Medical Protective Association Consent: A Guide for Canadian Physicians. They must understand that the informed consent form is simply documentary confirmation of consent explanations and not, in itself, informed consent. They must know that printed materials provided in advance describing the procedure and its risks and benefits are adjunctive and do not constitute informed consent. They must be aware that legal action may occur many years after the fact and that a valuable defence is a personal note recording the physician/patient interview during which time the endoscopist should solicit and answer questions. The contemporaneous progress note can be invaluable and is highly recommended.

\section{BIBLIOGRAPHY}

The Canadian Medical Protective Association. Consent: A Guide for Canadian Physicians, 3rd edn. Ottawa: The Canadian Medical Protective Association, 1996.

American Society of Gastrointestinal Endoscopy, American Gastroenterological Association, American College of Gastroenterology (joint effort). Informed Consent for Gastrointestinal Endoscopy. ASGE publication 1010. Manchester: ASGE, 1986.

American Society of Gastrointestinal Endoscopy. Risk Management An Information Resource Manual. Manchester: ASGE.

Guidelines for the practice of gastrointestinal endoscopy. A statement from the South African Gastroenterology Society (SAGES) Council. South Afr Med J 1993;83:761-75.

Pereira SP, Hussaini SH, Wilkinson ML. Informed consent for upper gastrointestinal endoscopy. Gut 1995;37:151-3.

Plumeri P. Informed consent and the gastroenterological endoscopist. Gastrointest Endosc 1985;31:218-21.

Zuccaro G. Informed consent for gastroenterological procedures. Gastrointest Endosc 1995;41:522-4. 


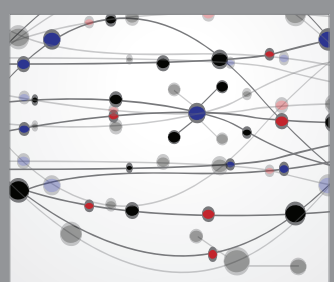

The Scientific World Journal
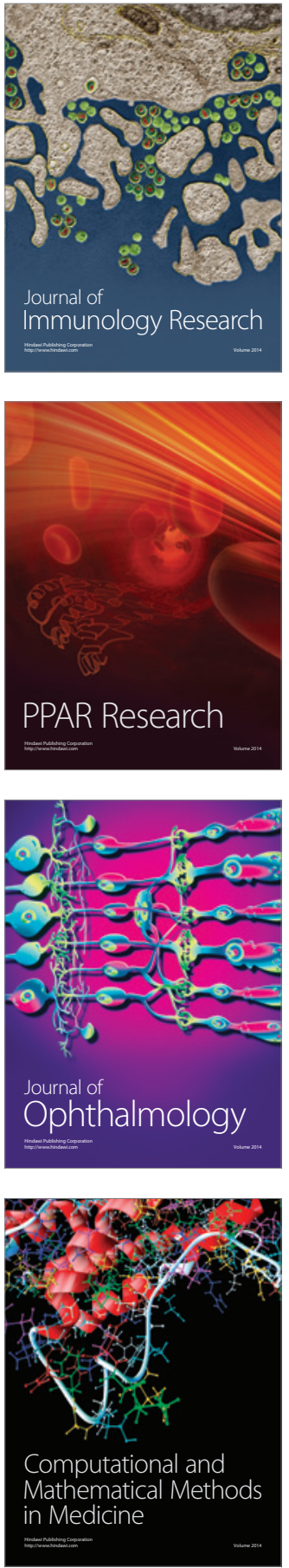

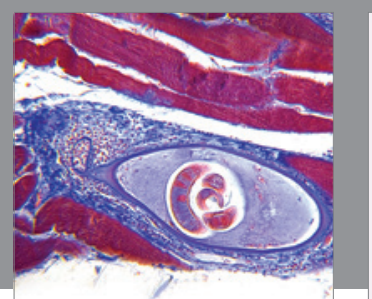

Gastroenterology Research and Practice

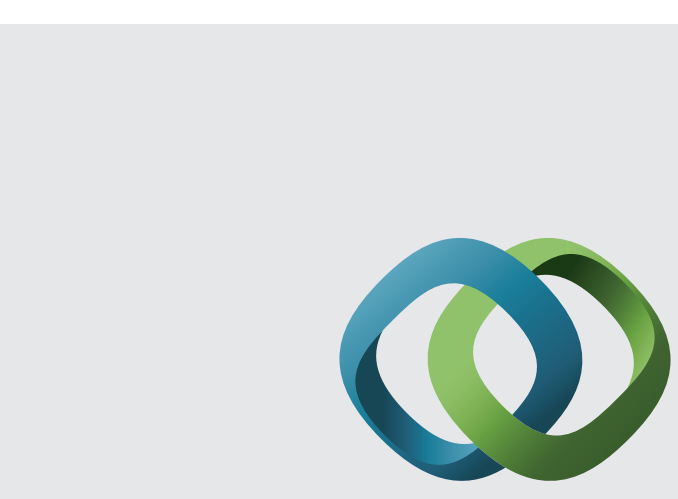

\section{Hindawi}

Submit your manuscripts at

http://www.hindawi.com
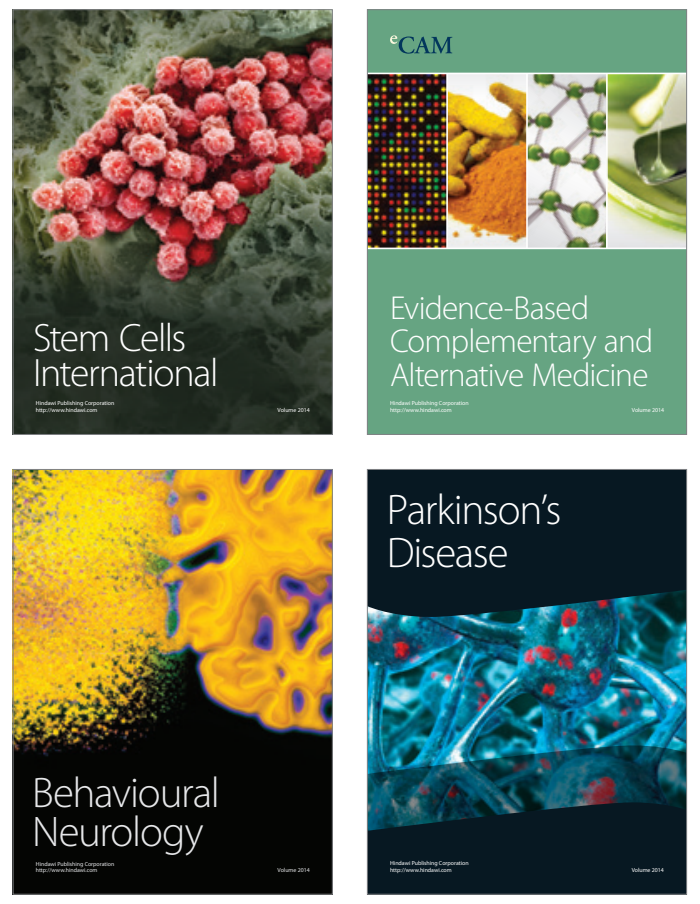
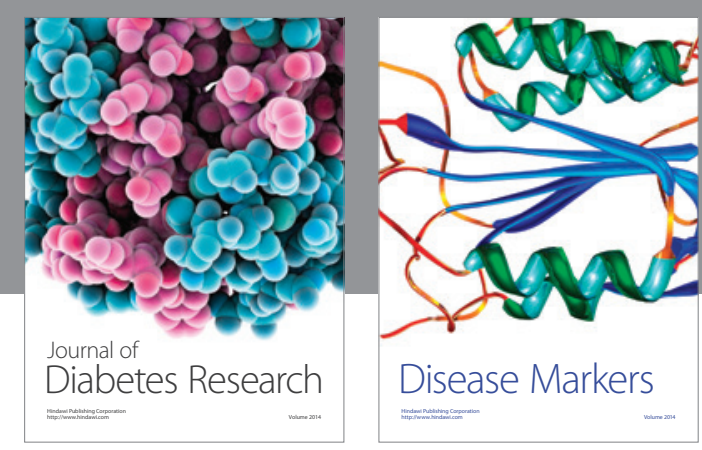

Disease Markers
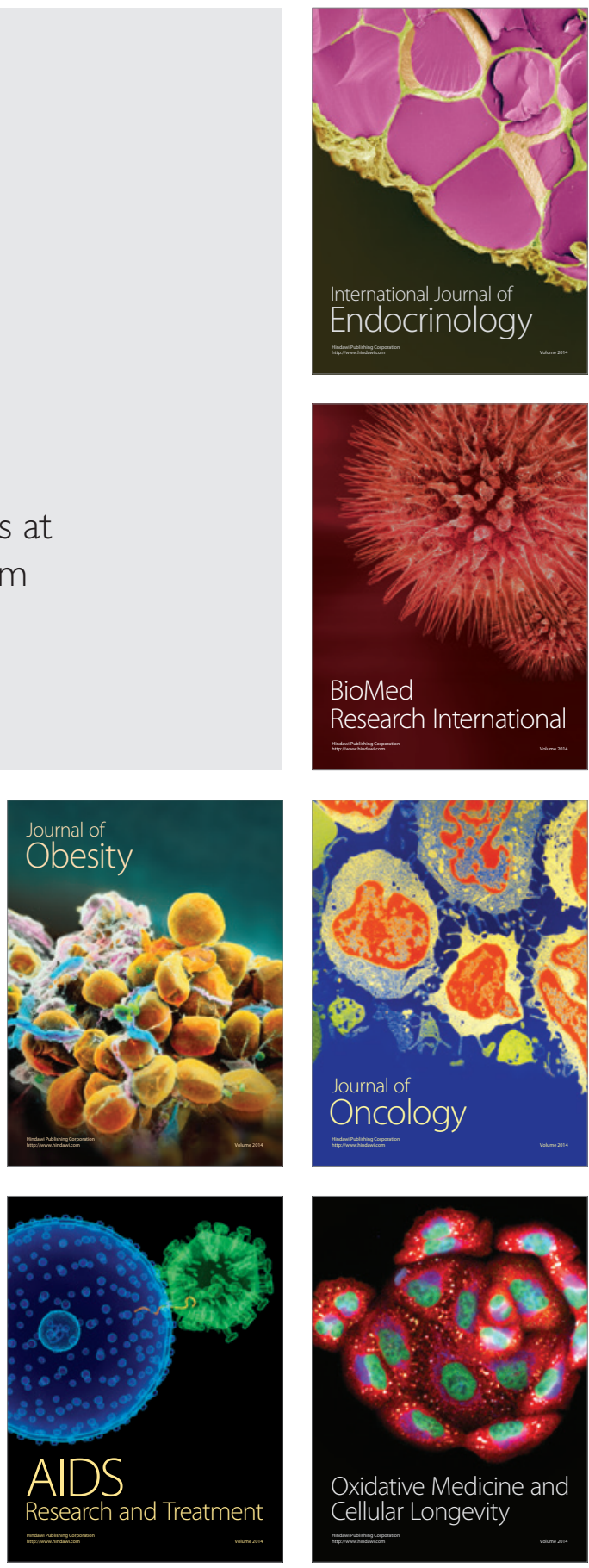